\title{
Biomedical and Health Informatics Education - the IMIA Years
}

\author{
J. Mantas \\ Health Informatics Laboratory, Department of Nursing, School of Health Sciences, National and \\ Kapodistrian University of Athens, Greece
}

\begin{abstract}
Summary
Objective: This paper presents the development of medical informatics education during the years from the establishment of the International Medical Informatics Association (IMIA) until today. Method: A search in the literature was performed using search engines and appropriate keywords as well as a manual selection of papers. The search covered English language papers and was limited to search on papers title and abstract only.

Results: The aggregated papers were analyzed on the basis of the subject area, origin, time span, and curriculum development, and condusions were drawn.

Conclusions: From the results, it is evident that IMIA has played a major role in comparing and integrating the Biomedical and Health Informatics educational efforts across the different levels of education and the regional distribution of educators and institutions. A large selection of references is presented facilitating future work on the field of education in biomedical and health informatics.
\end{abstract}

\section{Keywords}

Education, medical informatics, health informatics, biomedical informatics, nursing informatics

Yearb Med Inform 2016;Suppl1:S92-102 http://dx.doi.org/10.15265/IY-2016-032 Published online August 2, 2016

\section{Introduction}

The historical evolution of medical informatics is rather short as compared to that of medicine and it is linked to the historical steps of computer science even though computer science began immediately during and after the Second World War, and first applications of computer science in medicine started about a decade later.

We know from earlier fields of science that no discipline can exist if no formal education is established to support it and elevate it to a scientific field. The International Medical Informatics Association (IMIA) was conceptualised and initiated in the late 1960's and early 1970's and one of its very first duties was to establish a working group in education. In this work, we will try to follow and analyse the progress of Education in the field of Medical Informatics during the days of IMIA. Different names with sometimes varying meanings have been suggested for our field of medical informatics. In this contribution, we will interchangeably use the terms medical informatics, biomedical informatics and health informatics as umbrella terms.

In an earlier published paper [1], we have reported a number of educational contributions through the years. For aggregation purposes, we will reiterate some of the important contributions made by the pioneering work of early researchers and of corresponding organisations and events. In this historical perspective, we understand that most of the early developments were trying to resolve specific issues that were based on the needs of the users on the field.

The first discussion about whether medical informatics is a scientific discipline or not occurred during a panel discussion held during the IMIA working conference in Heidelberg/Heilbronn where it was concluded that medical informatics is a separate discipline with its own methodology [2]. Computer-aided instruction was used on a larger scale after personal computers (PCs) were introduced that were less costly than the mainframes used before (e.g. in the PLATO (Programmed Logic for Automatic Teaching Operations) project of the University of Illinois [3]). In several medical faculties, academic units for medical informatics were created. These units carried out research projects but they also started educational programs in medical informatics or medical information science as it was then often called, especially in the US. The name 'medical informatics' originated in Europe where it was first used by Francois Grémy and Peter Reichertz [1]. The term informatics was used to distinguish the discipline from computer science as it was called in the US. Later, the terms health informatics and biomedical informatics came into use and in a very structured way, recommendations were developed to facilitate curriculum development [4]. A five-stage evolution of medical informatics has been described by Hasman, Mantas, and Zarubina [1] and is given below.

\section{The Initiation Stage}

Francois Grémy established the Technical Committee Four (TC4) of the International Federation of Information Processing (IFIP). Under his leadership, TC4 became independent from IFIP in 1977 and was then called the International Medical Informatics Association (IMIA). In 1974, for the first time, medical informatics education was discussed at a meeting in Lyon (France), organized by the international 
working group TC4 [5]. At that time, there were already some educational curricula in medical informatics. As early as 1969, Francois Grémy initiated a curriculum in medical applications of computer techniques at Pitié-Salpêtrière (Paris, France). Another meeting was organized in 1983 in Chamonix (France) [6]. John Anderson at King's College Hospital Medical School reported about his experience with research and education in medical informatics [7]. In the US, pioneering work was already under development in clinical and expert systems like MYCIN by EH Shortliffe. In the Soviet Union, medical informatics as a discipline (called medical cybernetics) began in the late fifties of the twentieth century, and the first medical informatics department was established in Leningrad in 1961. Salamon and Dusserre reported efforts to establish a medical informatics course in France [8]. In Belgium, Roger France introduced a course for medical students in which medical information processing using informatics methodology was taught to facilitate decision making [9]. In the Netherlands, the department of Medical Informatics was created in 1973 at the Free University, in Amsterdam, under the chairmanship of Jan van Bemmel [1013], and a separate four-year program in Medical Informatics was established by the University of Amsterdam in the early nineties [14]. In Germany, in as early as 1972, a medical informatics program was established [15]. This program was a collaboration of the University of Heidelberg and the School of Technology in Heilbronn. The names of Franz Leven, Jochen Möhr, and Reinhold Haux are associated with this program [16-22].

\section{The Guiding Stage}

In May 1969, in Germany, a model curriculum for informatics was prepared with support of the then existing societies for mathematics and communication technology (the German Informatics Society was founded later in the fall of 1969). Three types of informatics were defined: theoretical, technical, and practical informatics. About $75 \%$ of the curricula were devoted to these subjects. The remaining 25\% were assigned to an application field, like engineering, commerce, mathematics, or medicine [23].

In 1973, Peter Reichertz together with the German Informatics Society and the Association for Medical Documentation, Informatics, and Statistics (GMDS) organized a workshop to define a framework for education in medical informatics. From these educational variations, it can be concluded that medical informatics was considered then as a combination of medicine and informatics. According to Moehr, the inclusion of these topics proved that medical informatics was more than the union of medicine and informatics. One of the most important contributions of the conference was the creation of a vision of a new type of professional, the health informatician, and the specification of an integrated curriculum, which was more than a union of a subset of medicine and informatics. Jochen Moehr reported about this meeting in the IMIA Yearbook of 2004 [24]. In 1991, the Recommendations for Education and Training in Medical Informatics of the GMDS were published [25]. In 1981, a report about a model curriculum for doctoral-level programs in what was called health computing was published in the USA by the Association for Computing Machinery (ACM) [26].

In the Netherlands in 1987, recommendations for education and training in medical informatics were formulated by the Medical Informatics Subcommittee of the Committee for Medicine of the Royal Netherlands Academy of Arts and Sciences under the chairmanship of Jan van Bemmel. In the report 'Medical Informatics - Renewal in Medicine' it is noted that professionals in healthcare were increasingly confronted with computer systems [27, 28]. The report of the Panel on the General Professional Education of the Physician and College Preparation for Medicine (GPEP) of the Association of American Medical Colleges entitled 'Physicians for the Twenty-First Century' was used as starting point [29]. These latter recommendations were based on the subgroup report on Medical Information Science Skills, chaired by Nina Matheson and Donald A. B. Lindberg [30].
They observed that only a handful of American medical schools had the personnel and computer resources to provide education in the principles and operations of medical information systems.

To successfully implement the Information for Health programme (IfH) at the local level, the NHS Information Authority developed in 2001 competency profiles that identified skill and knowledge levels for NHS staff. These profiles provided guidance and baseline data for local staff training [31].

It is worth mentioning for historical reasons that in 1988, a course taught within the undergraduate curriculum of the Nursing School of the University of Athens was renamed from Medical Informatics to Health Informatics. It was the first time that we encountered this term, which was accepted at the end of the 1990's and beginning of the 2000's as the appropriate generic term reflecting our field in an official course title.

\section{Contagion Stage}

In 1976, the European Federation for Medical Informatics (EFMI) [32-37] was established and in 1979 TC4 of IFIP became an independent organization named IMIA. IFIP-TC4 and later IMIA's working group on education organized a number of working conferences dedicated to education in medical informatics. The first working group conference was held in 1974 in Lyon (France), where how to respond to the need for medical informatics education was discussed [5]. In 1983, a second working group meeting was held in Chamonix (France) [6]. Here several existing programs in medical informatics were discussed. Then next conferences were held in Victoria (Canada) in 1989, in Prague (Czech Republic) in 1990 [38], in Heidelberg/Heilbronn (Germany) in 1992, in Newcastle (Australia) in 1997, in Portland (USA) in 2003, in Athens (Greece) in 2005, and in Buenos Aires (Argentina) in 2008. Later educational meetings were conducted during MEDINFO conferences.

The importance of information systems for healthcare was then recognized by the European Community. The AIM (Advanced Informatics in Medicine) initiative was a 
research and development activity of the European Community managed through Directorate General XIII of the European Commission. Since hardly any curricula in health informatics existed, it was concluded that one of the tasks of EDUCTRA (Information Technologies for EDUCation and TRAining) had to be to define guidelines for developing curricula for various groups of professionals. The objective of the guidelines was to provide trainers with a framework according to which they could design their courses. These guidelines were produced and published in 1995 [39-41].

An Erasmus Inter-University Cooperation Programme (also funded by the European Commission) was developed at the MSc level with a focus on education in Health Informatics. The programme funded by Erasmus (from 1989 to 1998) and coordinated by the University of Athens (Greece) [42] was organized in two phases. More than twenty European Universities were exchanging professors and students in the implementation of this intensive Master's programme in Health Informatics. It was the first time that the term "Health Informatics" [43-89] was used in an official academic program and was academically appointed to represent our field. Other programs developed courseware [90]. In 1993, the joint European project EuroMISE (European Education in Medical Informatics, Statistics, and Epidemiology) started under the umbrella of the European Trans-European Mobility Scheme for University Studies (TEMPUS) programme. The idea was to teach the teachers in various fields including health informatics [91]. Furthermore, the IT EDUCTRA project approved in the Fourth Framework programme of the EU in 1995 [92], as well as the NIGHTINGALE project (Nursing Informatics Generic High-level Training In Nursing - General Applications for Learning and Education), again an EU financed project, was approved in 1995 [93]. The project was considered essential for planning and implementing a strategy to train the nursing profession in using and applying healthcare information systems. Various European Conferences on Health Telematics education were also organized [94-96] and a textbook in health informatics for nurses was compiled [97].

\section{Consolidation Stage}

From the 90s, the University of Maryland in Baltimore began to enter information collected on health/medical informatics programs worldwide into a database [98]. IMIA's Working Group 1 on Education and Training in Medical Informatics provided guidance on critical issues of policy and purpose. It was then decided to establish a website at the University of Heidelberg. The main goal was to give potential students easy access to a new version of the database [99].

IMIA identified the need to develop international recommendations for health informatics education and elaborated IMIA recommendations taking into account the various existing and mainly national recommendations. IMIA recommendations were published in 1999 and centred on the educational needs of healthcare professionals to acquire knowledge and skills in information processing and information and communication technology as needed and applied in medicine and healthcare [100]. These recommendations were received positively as can be concluded from the many citations. Because of the tremendous progress in and the evolution of our field of health informatics, the contents of these recommendations became partially out-dated. Therefore, a first revision of IMIA recommendations was published in 2010 [4]. The name of the domain area was changed to Biomedical and Health Informatics.

\section{Quality Control}

IMIA recommendations define the knowledge and skills necessary for the different types of health informaticians. In many countries, the quality of educational programs is monitored via an accreditation procedure. Independent of national programs, IMIA developed an accreditation procedure as a support for institutions that want to establish the quality of their program in health informatics at an international level [101].

\section{Methods}

In order to achieve our aim to present the development of medical informatics education during the years from the establishment of IMIA until today, an on-line query was conducted on the following databases: PubMed, Scopus, Google Scholar and ScienceDirect. The search was performed from October to December 2015. We focused on papers whose contents included subject areas, namely Bioinformatics, Biomedical Informatics, Health Informatics, Medical Informatics, Nursing Informatics, as well as related information about International Medical Informatics Association (IMIA). To find scientific contents related to our topic, specific keywords were used like: "Bioinformatics", "Computational Biology", "Biomedical Informatics", "Health Informatics", "Healthcare Informatics", "Medical Informatics", "Nursing Informatics", "Informatics" and "Imia". In addition, in order to locate papers in the areas of "Health Informatics/Healthcare Informatics", "Educational Programs", "Curriculum", "Training", and "Education", additional terms were used such as "Health Information Technology", "Health Information Science", "Health Information Courses", "Biomedical Informatics Programs", "Biomedical Informatics Educational Programs", "Health Informatics Programs", "Health Informatics Educational Programs", "Medical Informatics Programs", "Health Informatics Curriculum", "Health Informatics Curricula", "Medical Informatics Curricula", "Medical Informatics Curriculum", "Biomedical Informatics Curriculum", "Healthcare Informatics Curriculum", "Biomedical Informatics Training", "Continuing Professional Education", "Health Informatics Training", "Medical Informatics Training", "Health Informatics Education", "Biomedical Informatics Education", "Healthcare Informatics Education", "Medical Informatics Education", and "IMIA accreditation" (see Fig. 1). However, the final selection was performed taking into account the title, keywords, and abstract. The overall number of papers selected for further analysis was 177 . It should be noted that the intention of the author of this article 


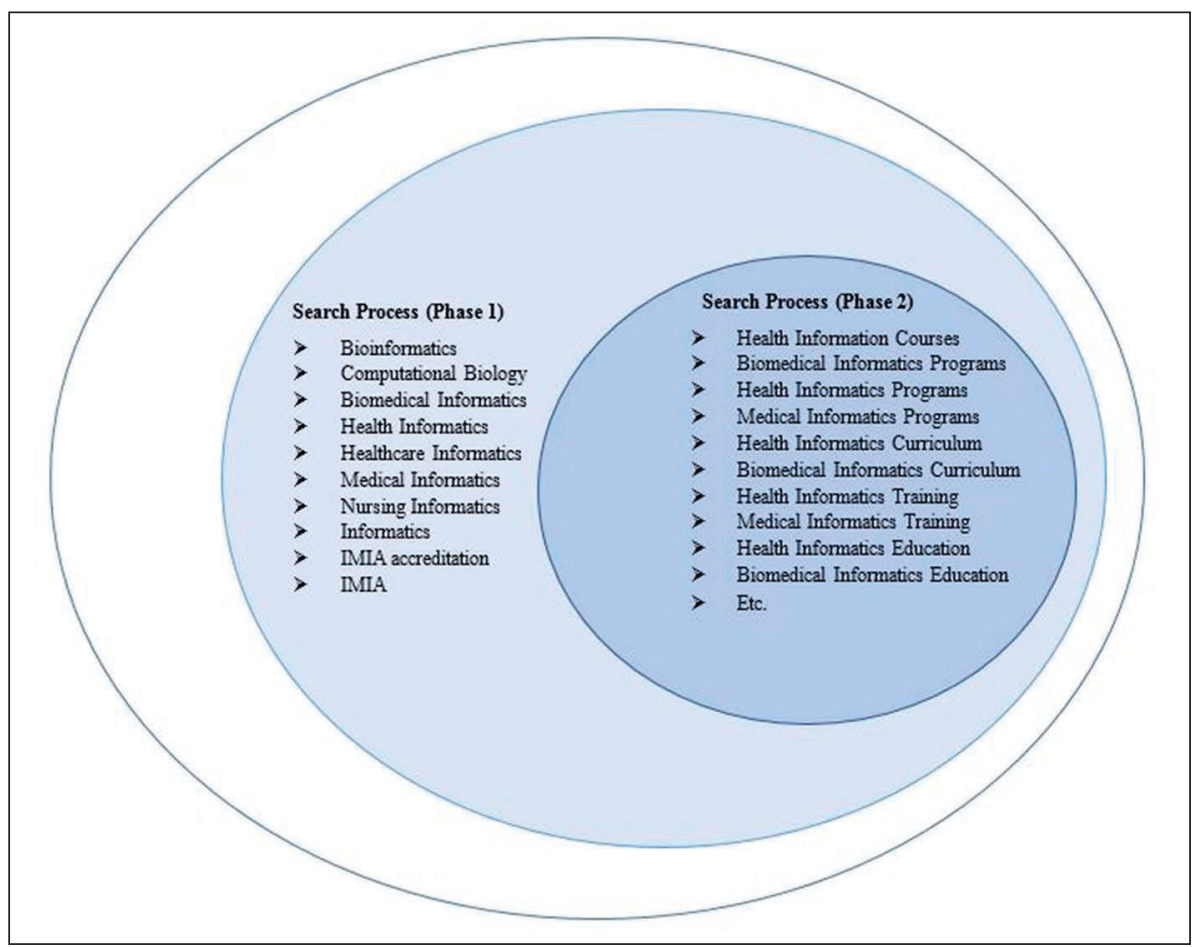

Fig. 1 The search process of papers related to Biomedical Informatics Education

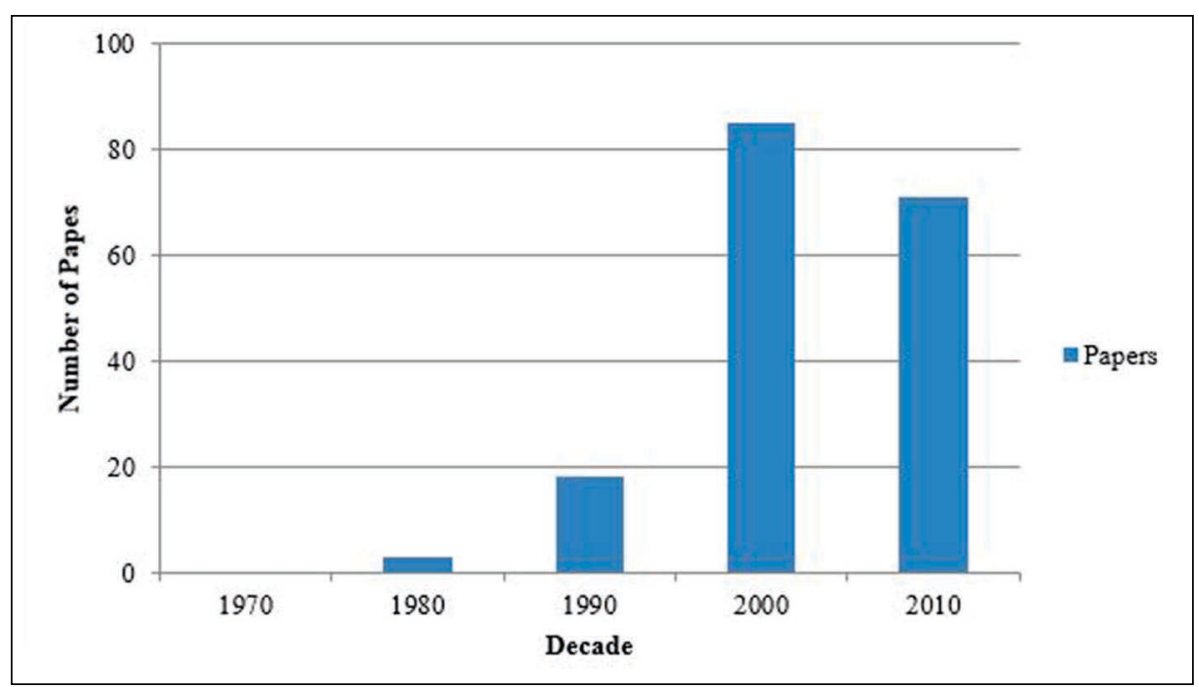

Fig. 2 Number of published papers per decade $(\mathrm{n}=177)$

was to provide a wide selection of papers to be included in the analysis.

The time period used as a search criterion for this research was from 1967, the early establishment of IMIA, until December 2015. In particular, in the follow up analysis, we wanted to extract descrip- tive statistics on the contents of the papers and the origin of the publications. Papers with information on academic programs, theme areas, curriculum, evaluation, and accreditation process were located and an analysis of the date of publication was performed.

\section{Results}

A descriptive analysis was first performed on the yearly (actually, in decades) frequency of the papers, the regional distribution of the origin of the papers, the theme areas, the educational level, the evaluation, and the accreditation.

\section{a Time Span}

The distribution per decade of the retained papers appears in Fig. 2. Few papers were published in the early years. The creation of the IMIA working group on education and the frequent annual meetings that were organized mobilized educators and researchers. They published their results in the later and recent years, as seen in the figure. From the Fig. 2, it is clear that a rapid increase in the number of publications occurred after the 1990's coinciding with the direct involvement of the IMIA working group on education facilitating the dissemination of educational activities in biomedical and health informatics.

\section{b Regional Distribution}

The analysis of the retained papers according to the origin of the first author shows that North America and Europe played an important role in the advancement and implementation of educational programs in medical informatics throughout the years. However, considering the population of those two continents, one has to emphasize the important progress in recent years of other regions (see Figures 3 and 4).

\section{c Thematic Areas}

\section{i Frequency of papers using domain search terms}

Table 1 displays the frequency of the papers using domain keywords as search terms in the papers retained for the analysis. The terms "Health Informatics" and "Medical Informatics" are the most frequently met; time-wisely, "Health Informatics" appears later than "Medical Informatics". "Nursing Informatics" [102-134] is the third most frequent term exemplifying the importance that informatics increasingly played in Nurs- 
ing in the recent years. On the other hand, "Bioinformatics" [135-136], is frequently used although it appeared in the literature quite later than the other terms.

\section{ii Frequency of papers using educational term keywords}

As shown in Table 2, the most frequent papers appear when searched with the search term "Education" and secondly "Curriculum". "Education" was expected to be the most frequently met, since it is rather generic. "Curriculum" was often encountered because many efforts on developing curricula were reported in the literature. It should be noted that the keyword IMIA could be found in a few publications because of the previously mentioned educational recommendations

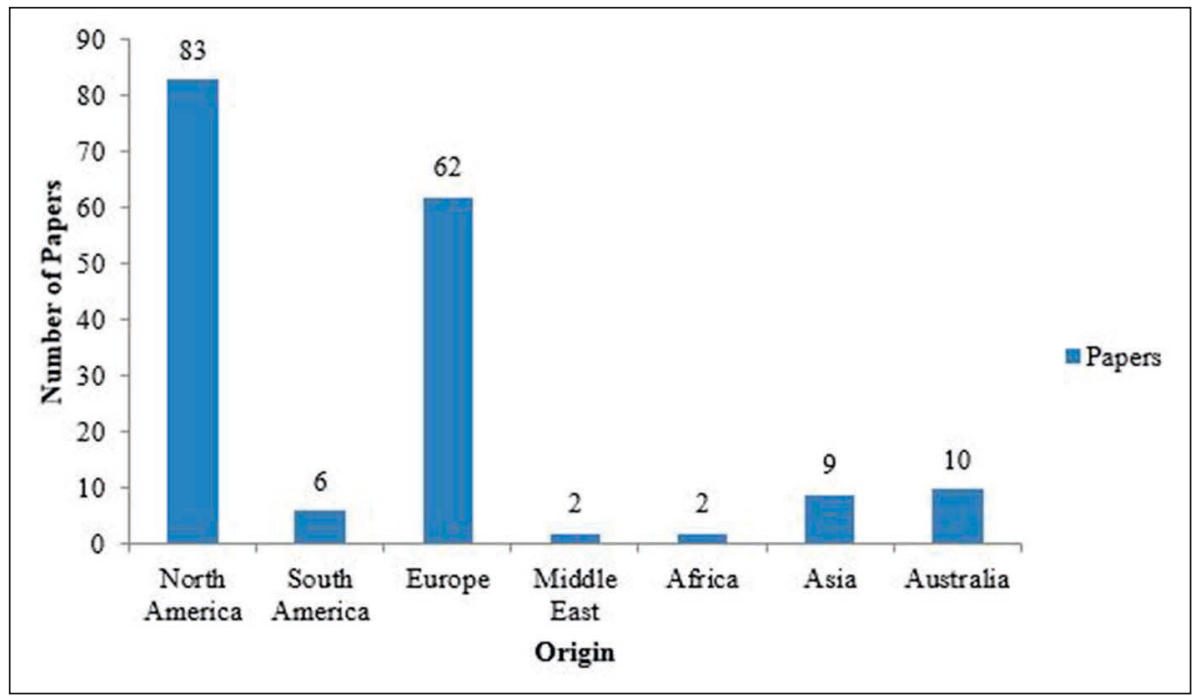

Fig. 3 Number of published papers per origin ( $\mathrm{n}=174$, some authors had multiple origins and the corresponding papers were removed)

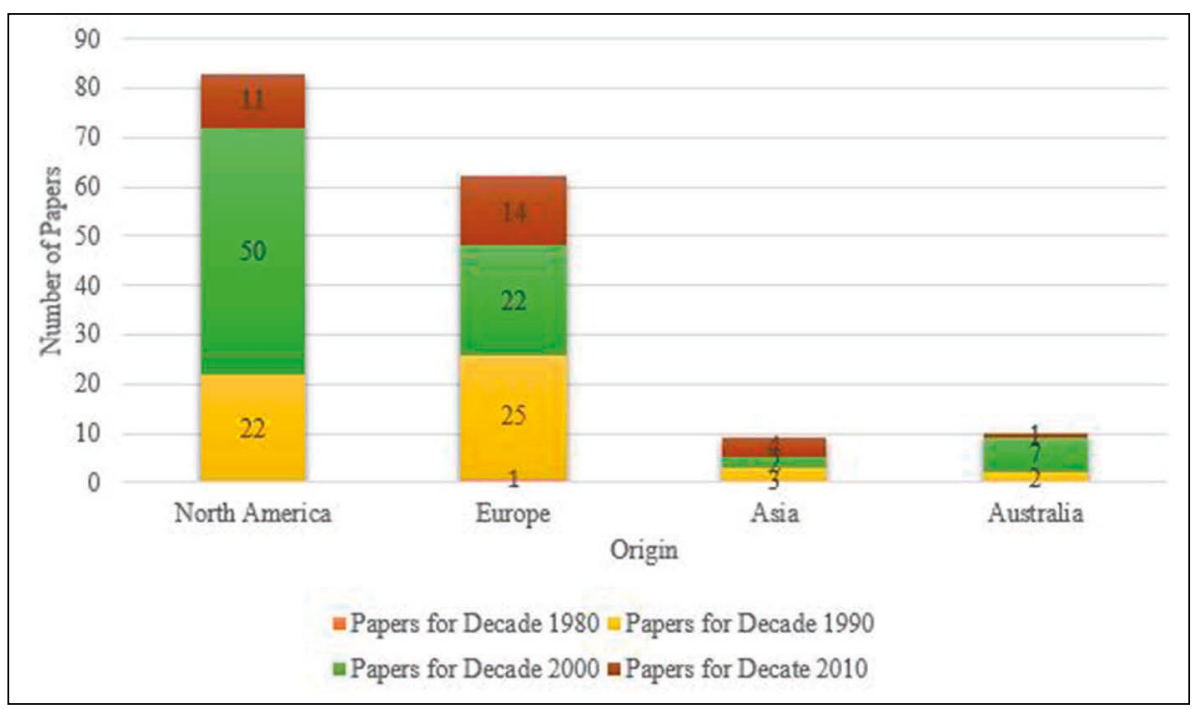

Fig. 4 Number of published papers per origin and decade and lately because of historical articles. The IMIA accreditation is mentioned in several articles, as the effort is still minimal.

The above-mentioned generic terms are related not only to the educational field but also to research as a number of research funded programs have focused on the whole spectrum of biomedical informatics (see [137-159]) as described in Fig. 5.

\section{d Curriculum Development}

The majority of the papers describe educational programs at all levels of education (undergraduate, graduate, and doctoral). Also a number of publications are focusing on shorter periods of education, such as specialty training programs, distance / e-learning programs, life-long learning, vocational training, and certificate programs (Fig. 7). A few articles provide full documentation of the description of the curriculum, whereas the rest is focused on the curriculum development process. In the early years of medical informatics [160-212], incorporating computer science courses in medical/health sciences curricula was a difficult task. The conservative approach regarding medical curriculum modifications in medical schools was one of the major factors of delaying the adoption of medical informatics courses in medical core curricula. In most papers on educational programs, there is a description of the evaluation process to validate the acceptance of the curriculum and the implementation of the program. The majority of educational programs were adapted to the needs of the local societies and national healthcare systems; the diversity of curricula reflects those diverse needs. Later articles tend to describe a curriculum based on latest educational descriptions. As a result, we have papers with a detailed description of objectives, learning outcomes, and skills. This kind of curriculum description is more structured, easier to be evaluated, maps educational needs, and reflects the professional requirements. IMIA-developed educational recommendations have utilized a structured approach to demonstrate how a biomedical informatics curriculum can be developed at any educational level. 


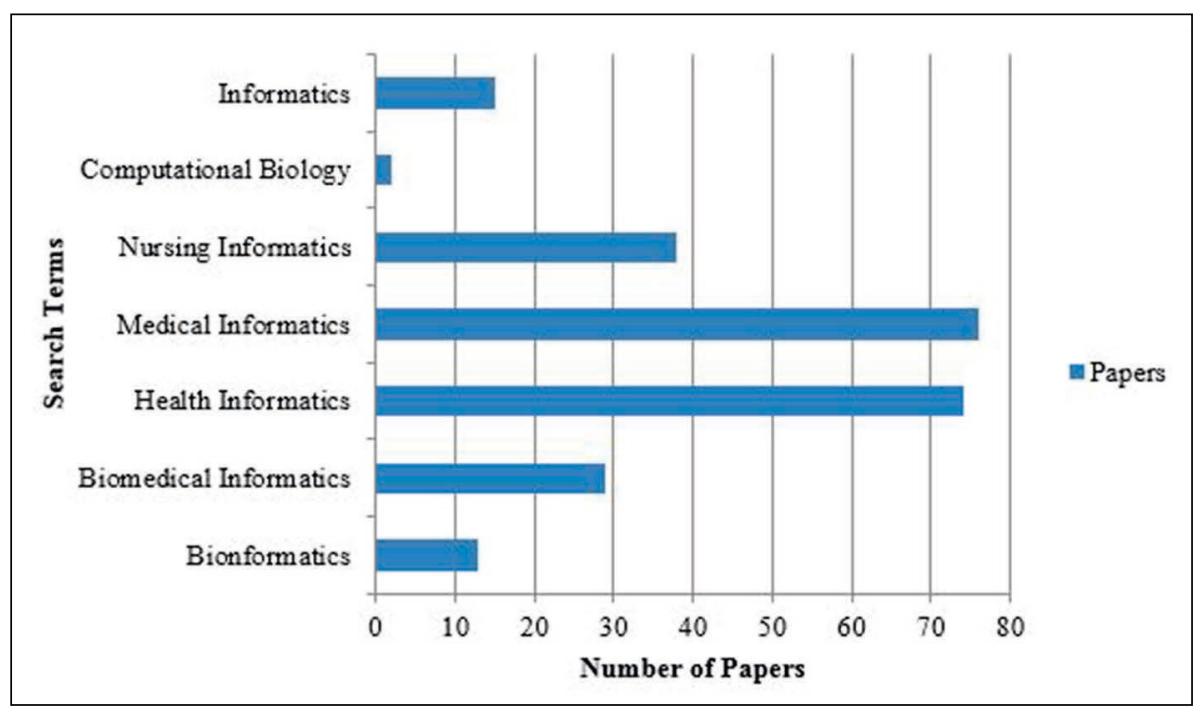

Fig. 5 Number of papers per generic Medical Informatics search term

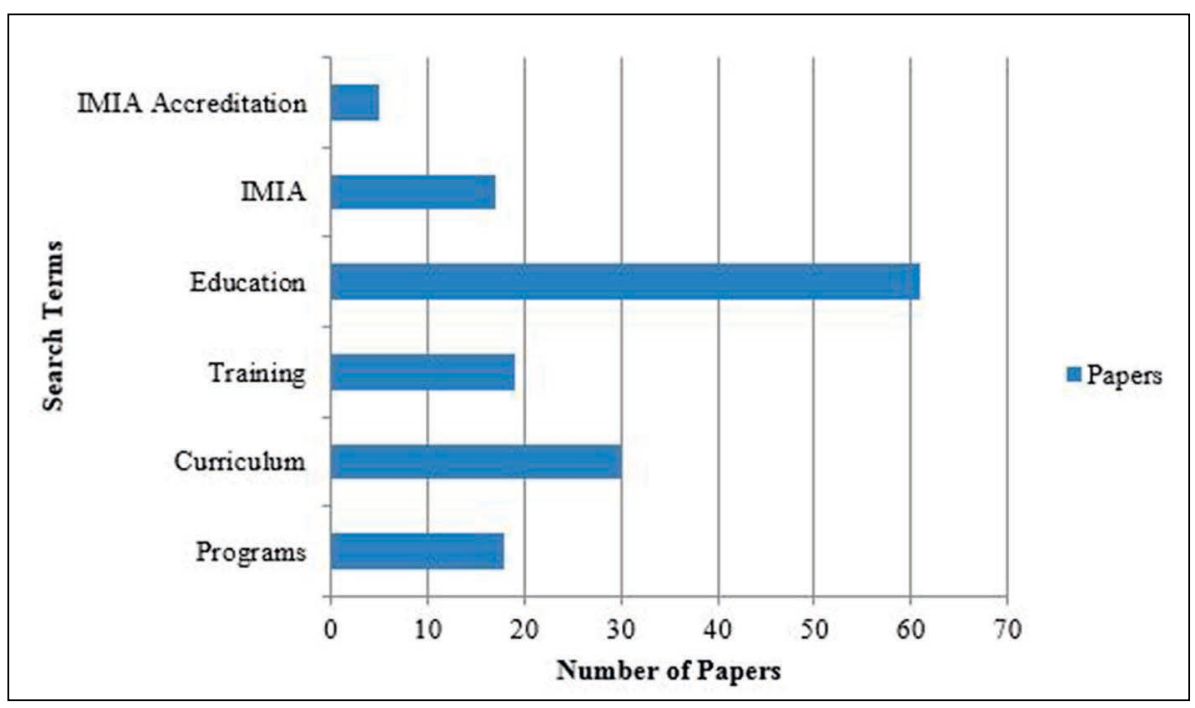

Fig. 6 Number of papers per educational Medical Informatics search term

\section{e Accreditation and Evaluation}

In the later years, emphasis focused on both evaluation and accreditation processes. In most countries, a national evaluation committee exists that evaluates in specific periods all educational programs at any level. However, a few organizers of educational programs expressed the need for a more objective outside body to evaluate and accredit programs for international reputation. To this end, IMIA has provided an accreditation
Table 1 Number of papers per generic Medical Informatics search term (multiple terms may exist per paper).

\begin{tabular}{|l|c|}
\hline Search Terms & $\begin{array}{c}\text { Number } \\
\text { of Papers }\end{array}$ \\
\hline Bioinformatics & 13 \\
Biomedical Informatics & 29 \\
Health Informatics & 74 \\
Health Information technology & 4 \\
Health information science & 1 \\
Health informatics courses & 1 \\
Medical Informatics & 76 \\
Nursing Informatics & 38 \\
Computational Biology & 2 \\
Informatics & 15 \\
\hline
\end{tabular}

Table 2 Number of papers per educational Medical Informatics search term (multiple terms may exist per paper).

\begin{tabular}{|l|c|}
\hline Search Terms & $\begin{array}{c}\text { Number } \\
\text { of Papers }\end{array}$ \\
\hline Programs & 18 \\
Biomedical informatics programs & 2 \\
Biomedical informatics educational & 3 \\
programs & \\
Health informatics programs & 5 \\
Health informatics educational programs & 2 \\
Medical informatics programs & 2 \\
Curriculum & 30 \\
Health informatics curriculum & 2 \\
Health informatics curricula & 2 \\
Medical informatics curricula & 1 \\
Medical informatics curriculum & 5 \\
Biomedical informatics curriculum & 2 \\
Healthcare informatics curriculum & 2 \\
Training & 19 \\
Biomedical Informatics Training & 1 \\
Continuing professional education & 1 \\
Health informatics training & 2 \\
Medical informatics training & 2 \\
Education & 61 \\
Health informatics education & 18 \\
Biomedical informatics education & 1 \\
Healthcare informatics education & 2 \\
Medical informatics education & 13 \\
IMIA (recommendations, history) & 17 \\
IMIA Accreditation & 5 \\
\hline
\end{tabular}




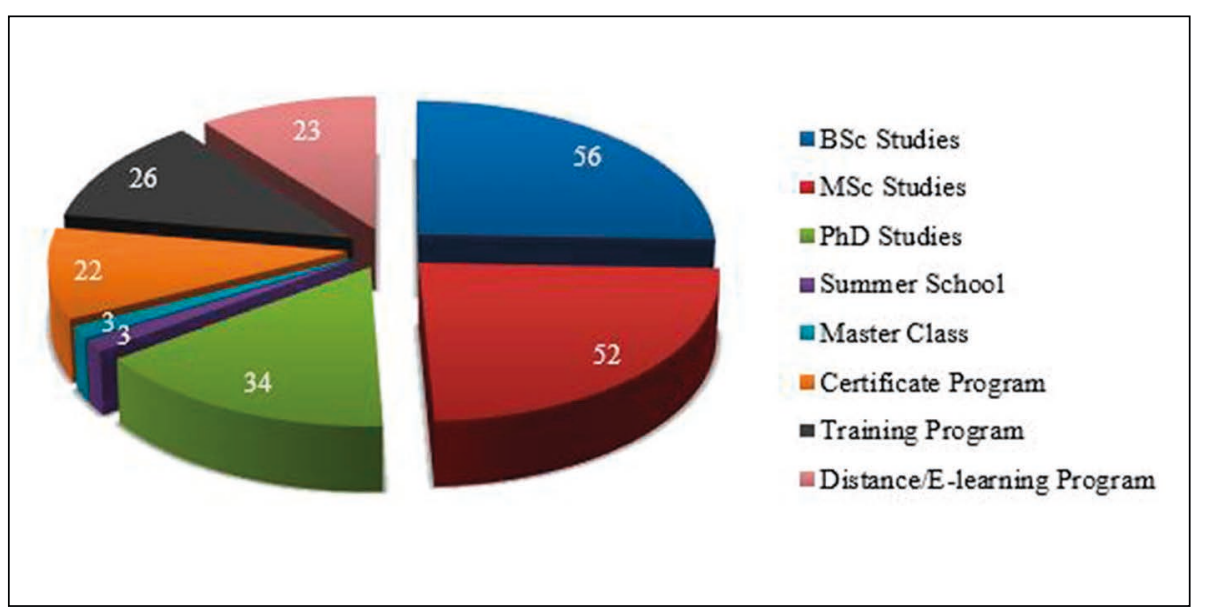

Fig. 7 Number of papers per curriculum

\section{Limitations}

This review article has a number of limitations. First, the literature search was limited to English language papers. In the first years of IMIA, other papers written in languages such as French, German, Russian, and Japanese may have had a strong significance in the evolving field. Second, very few papers exist in the years from 1967 to 1987, which may be due to the lack of registration and classification of the articles in the now well-known bibliographical databases; so, the search may be incomplete for those years. Third, the search of papers in Nursing Informatics education may not be complete as other databases are used frequently in Nursing such as CINAHL, which was not used in this current review. Furthermore, for certain questions, access to the full paper was required to extract information, especially in the curriculum section. As access to the full paper was sometimes limited, the extracted information was in some cases incomplete. In summary, this study's limitations include the use of only English language papers and the search on title and abstracts only. Furthermore, we only focused on the literature and did not cover the complete spectrum of contributions of education under IMIA-related societies and groups. Finally, we consider that in certain sections of the review, a further and a more in depth analysis is still required.

\section{Conclusions}

The paper presents an overview of the Medical Informatics educational activities during the years of IMIA's existence. In the introductory part, a kind of stepwise approach is followed depicting a series of important accomplishments throughout the years. The five stages described are based on a previous publication [1]. The retrieved papers were analyzed in a descriptive way in terms of time distribution, regional origin of the publication, contents in terms of keywords, curriculum description, and evaluation and accreditation processes. Limitations of this research are described.

It is evident that the remarkable local and individual efforts made to develop and establish medical informatics educational courses were put forward - first as part of medical/health sciences curricula and later in specific programs at the postgraduate and undergraduate levels. IMIA acted in the late 1980's as a forum for exchanging experiences and ideas and later as a catalyst to unify and integrate the different initiatives, with the development of educational recommendations as guidelines, which facilitated the development of new programs across the globe and permitted the comparison between different programs. Therefore, IMIA has transformed the "ego-system" (in a good sense) of the early years in an "ecosystem" of educators and institutions truly dedicated to the expansion of biomedical and health informatics education.
The later process of accreditation initiated by IMIA can provide a very powerful tool to the Universities/Institutions seeking for international acknowledgment of their accomplishments and to the IMIA community for expanding in all regions and continents the biomedical and health informatics discipline.

\section{Acknowledgments}

The author would like to thank the editors of this volume for their kind and honorable invitation, their patience, and their support. The author would like to acknowledge that excerpts from the paper referenced in [1] were employed especially in the introductory part of this paper. Sincere thanks to all colleagues who participated during these many years to the IMIA Working Group on Education, they have contributed through their efforts to these fruitful results and have authored numerous, high quality papers, over half a century. Special thanks go to the reviewers of the paper exemplifying to the author from minor errors to very important limitations giving incentives for further in depth research. Finally, the author wants to thank Miss Katia Kolokathi of the Laboratory of Health Informatics, Department of Nursing, School of Health Sciences, National and Kapodistrian University of Athens, Greece, for her assistance in the preparation of this article through the tedious typing and compilation of the extensive literature, and the provision of tables and graphs.

\section{References}

1. Hasman A, Mantas J, Zarubina T. An abridged history of medical informatics education in Europe. Acta Inform Med 2014;22(1):25-36.

2. Protti DJ, Van Bemmel JH, Gunzenhäuser R, Haux R, Warner H, Douglas JV, Lang E. Can Health/ Medical Informatics be regarded as a separate discipline? Methods Inf Med 1994;33:318-26

3. Levy AH. Experiences with PLATO in medical education. In: Pagès J-C, Levy AH, Grémy F, Anderson J, editors. Meeting the challenge: informatics and medical education. Amsterdam, North-Holland; 1983. p. 201-6.

4. Recommendations of the International Medical Informatics Association (IMIA) on education in health and medical informatics. Methods Inf Med 2000;39(3):267-77.

5. Anderson J, Grémy F, Pagès, J-C, editors. Education in Informatics of Health Personnel. IFIP Medical Informatics Monograph Series 1. Amsterdam, North-Holland; 1974. 
6. Pagès J-C, Levy AH, Grémy F, Anderson J, editors. Meeting the challenge: informatics and medical education. Amsterdam, North-Holland; 1983.

7. Anderson J. Experiences with learning and teaching in medical informatics. In: Pagès J-C, Levy $\mathrm{AH}$, Grémy F, Anderson J, editors. Meeting the challenge: informatics and medical education. Amsterdam, North-Holland; 1983. p. 49-54.

8. Salamon R, Dusserre L. Is the teaching of medical informatics possible? The situation in France. In: Pagès J-C, Levy AH, Grémy F, Anderson J, editors. Meeting the challenge: informatics and medical education. Amsterdam, North-Holland; 1983. p. 143-7.

9. Roger FH. A structured clinical presentation of case to medical students. In: Pagès J-C, Levy $\mathrm{AH}$, Grémy F, Anderson J, editors. Meeting the challenge: informatics and medical education. Amsterdam, North-Holland; 1983. p. 193-199.

10. Van Bemmel JH. A comprehensive model for medical information processing. Methods Inf Med 1983;22:124-30.

11. Van Bemmel JH, Hasman A, Sollet PCGM, Veth AFL. Training in medical informatics. Comput Biomed Res 1983;16:414-32.

12. Hasman A. Training in medical informatics. The use of computers for diagnostic purposes. Int J Biomed Comput 1982;13:109-18.

13. Van Bemmel JH, Gelsema ES, Hasman A, Schutte $\mathrm{F}$, Sollet PCGM, Vet AFL. Curricula in medical informatics - experience during 10 years in Amsterdam. In: Pagès J-C, Levy AH, Grémy F, Anderson $\mathrm{J}$, editors. Meeting the challenge: informatics and medical education. Amsterdam, North-Holland; 1983. p. 55-65.

14. Tuinstra CL, Verveen AA. Information science in the medical curriculum; principles and practice at Leiden University. In: Pagès J-C, Levy AH, Grémy F, Anderson J, editors. Meeting the challenge: informatics and medical education. Amsterdam, North-Holland; 1983. p. 127-34.

15. Reichertz P. Curricula in medical informatics. Experiences in the Federal Republic of Germany. In: Pagès J-C, Levy AH, Grémy F, Anderson J, editors. Meeting the challenge: informatics and medical education. Amsterdam, North-Holland; 1983. p. 79-95.

16. Möhr JR, Leven FJ. The Heidelberg/Heilbronn curriculum of medical informatics. In: Pagès J-C, Levy AH, Grémy F, Anderson J, editors. Meeting the challenge: informatics and medical education. Amsterdam, North-Holland; 1983. p. 97-106.

17. Möhr JR, Leven FJ, Rothemund M. Formal education in medical informatics. Review of ten years' experience with a specialized university curriculum. Methods Inf Med 1982;21:169-80.

18. Haux R, Leven FJ. Twenty years medical informatics education at Heidelberg/Heilbronn: Evolution of a specialized curriculum for medical informatics. Methods Inf Med 1994;33:285-9.

19. Leven FJ. Curriculum for medical informatics at the University of Heidelberg/School of Technology Heilbronn. Methods Inf Med 1994;33:262-7.

20. Leven FJ, Haux R. Twenty five years of medical informatics education at Heidelberg/Heilbronn: discussion of a specialized curriculum for medical informatics. Int J Biomed Comp 1998;50:31-42.
21. Leven FJ, Knaup P, Schmidt D, Wetter T. Medical informatics at Heidelberg/Heilbronn: status evaluation - new challenges in a specialised curriculum for medical informatics after thirty years of evolution. Int J Med Inform 2004;73(2): 117-25.

22. Knaup P, Haag M, Leven FJ and Dickhaus H. Challenges in the Evolution of the Medical Informatics Program at Heidelberg/Heilbronn (Germany). Methods Inf Med 2009; 48: 66-75.

23. Moehr JR. The quest for identity of health informatics and for guidance to education in it - The German Reisensburg Conference of 1973 Revisted. In: Haux R, Kulikowski C, editors. Yearbook of Medical Informatics 2004; Stuttgart, Schattauer; 2004. p. 200-9.

24. Moehr JR. English translation of the minutes of the invitational workshop Goals, contents and methods for education in medical informatics. In: Haux R, Kulikowski C, editors. Yearbook of Medical Informatics 2004; Stuttgart, Schattauer; 2004. p. 210-9.

25. Haux R, Dudeck J, Gaus W, Leven FJ, Kunath H, Michaelis J, Pretschner DP, Sonntag H-G, Thurmayr R, Wolters E. Recommendations of the German Association for Medical Informatics, Biometry and Epidemiology for education and training in medical informatics. Methods Inf Med 1992:31:60-70.

26. Duncan KA, Austing RH, Katz S, Pengov RE, Pogue RE, Wasserman AI. A model curriculum for doctoral-level programs in health computing, Report of the ACM committee on curriculum for health computing education. Baltimore: Association for computing machinery; 1981.

27. Van Bemmel JH, Festen C, editors. Medical informatics renewal in medicine (in Dutch with English summary). Amsterdam: Committee for Medicine of Royal Netherlands Academy of Arts and Sciences; 1987.

28. Hasman A. Recommendations for medical informatics training in The Netherlands. Methods Inf Med 1994;33:308-11.

29. Physicians of the twenty-first century. The GPEP Report. Washington: Association of American Medical Colleges; 1984.

30. Matheson N, Lindberg DAB. Subgroup Report on medical information skills. J Med Educ 1984;59:155-9.

31. NHS Information Authority. Health Informatics Competency Profiles for the NHS. Reference No: 2001-IA-523: 2001.

32. Hofdijk J, Weber P, Mantas J, Mihalas G, Masic I. A Short Factography about IMIA and EFMI. Acta Inform Med 2014;22(1):71-8.

33. Marcano-Cedeno A, Wageih MA, Gomez EJ, Mantas J. IMIA Dynamic Accreditation Procedure: Suggestions, Simplicity and Efficiency. Stud Health Technol Inform 2015;213:115-8.

34. Haux R, Murray PJ. On IMIA's International Activities in Health and Biomedical Informatics Education. Methods Inf Med 2010;49(3):305-9.

35. Ball MJ, van Bemmel JH, Kaihara S. IMIA Presidential Retrospectives on Medical Informatics. Yearb Med Inform 2007:165-75.

36. Huesing SA. IMIA-A 40 Year Organizational Overview. Yearb Med Inform 2007:186-91.

37. Murray PJ. The IMIA Strategic Plan-Towards IMIA 2015. Yearb Med Inform 2008:7-15.
38. Van Bemmel JH, Zvarova J. Knowledge, information and medical education. Amsterdam, North-Holland; 1990.

39. Hasman A, Sosa M. Review of the state-of-the-art in education and training of health informatics in Europe. Comput Methods Programs Biomed 1995;48(1-2):183-8.

40. Hasman A, Albert A, Wainwright P. Klar R, Sosa $\mathrm{M}$, editors. Education and training in healthcare informatics in Europe. Stud Health Technol Inform 1995:25.

41. Hasman A, Albert A. Education and training in health informatics: guidelines for European curricula. Int J Med Inform 1997;45:91-110.

42. Diomidus M, Mantas J. Assessing the progress of the M.Sc. course in health informatics under the ERASMUS programme. Int J Med Inform 1998;50:159-63.

43. Marin HF, Massad E, Marques EP, Ohno-Machado L. International training in health informatics: a Brazilian experience. Stud Health Technol Inform 2004;107(Pt 2):898-902.

44. Hasman A. Education and training in health informatics. Comput Methods Programs Biomed 1994;45(1-2):41-3.

45. Haux R. Health and medical informatics education: perspectives for the next decade. Int J Med Inform 1998;50(1-3):7-19.

46. Johnson SB, Friedman RA. Bridging the gap between biological and clinical informatics in a graduate training program. J Biomed Inform 2007:40(1):59-66.

47. De Gagne JC, Bisanar WA, Makowski JT, Neumann JL. Integrating informatics into the BSN curriculum: a review of the literature. Nurse Educ Today 2012;32(6):675-82.

48. Möhr JR. On fortune telling for health informatics. Int J Med Inform 2002;66(1-3):95-106.

49. Hovenga EJ. Globalisation of health and medical informatics education--what are the issues? Int J Med Inform 2004;73(2):101-109.

50. Gatewood L, Limburg M, Gardner R, Haux R, Jaspers M, Schmidt D, et al. International Master Classes in health informatics. Int J Med Inform 2004;73(2):111-6.

51. Green CJ, van Gyn GH, Moehr JR, Lau FY, Coward PM. Introducing a technology-enabled problem-based learning approach into a health informatics curriculum. Int J Med Inform 2004;73(2):173-179.

52. Murphy J, Stramer K, Clamp S, Grubb P, Gosland J, Davis S. Health informatics education for clinicians and managers-what's holding up progress? Int J Med Inform 2004;73(2):205-13.

53. Garde S, Harrison D, Hovenga E. Skill needs for nurses in their role as health informatics professionals: a survey in the context of global health informatics education. Int J Med Inform 2005;74(11-12):899-907.

54. Araujo J, Pepper C, Richards J, Choi M, Xing J, Li $\mathrm{W}$. The profession of public health informatics: still emerging? Int J Med Inform 2009;78(6):375-85.

55 . Hovenga EJ. Health and medical informatics education for nurses and health service managers. Int J Med Inform 1998;50(1-3):21-9.

56. Bouman LN, Zwetsloot-Schonk JH, Jaspers MW, Louter GL, Timmers T. The graduate training in medical information sciences in the Academic 
Medical Centre at the University of Amsterdam. Int J Med Inform 1998;50(1-3):151-7.

57. Grant AM, Tremblay K. The need for a coherent curriculum and supported infrastructure in health informatics education--the HEALNet experience. Int J Med Inform 1998;50(1-3):165-70.

58. Nøhr C, Bygholm A, Hejlesen O. Strategic planning of the master programme in health informatics at Aalborg University: targeting and updating the programme, to meet explicit customer needs. Int J Med Inform 1998:50(1-3):207-13.

59. Hasman A. Education and health informatics. Int J Med Inform 1998;52(1-3):209-16.

60. Lun KC. Health informatics in the Asia Pacific region. Int J Med Inform 1999:55(1):3-7.

61. Gray K, Dattakumar A, Maeder A, Chenery H. Educating future clinicians about clinical informatics: A review of implementation and evaluation cases. European J Biomed Inform 2011;7(2):48-57.

62. Manifava E, Kolokathi A, Mantas J. Exploring the biomedical and health informatics educational programs in Europe. Stud Health Technol Inform 2014;202:67-70

63. Asiri HA. Challenges of the Health Informatics Education in the Kingdom of Saudi Arabia: What Stands in Our Way?. Journal of Health Informatics in Developing Countries 2014;8(1):26-35.

64. Strauss S. Canadian medical schools slow to integrate health informatics into curriculum. CMAJ 2010;182(12):551-2.

65. Mantas J. Postgraduate studies in health informatics in Greece. Stud Health Technol Inform 2005;116:261-6.

66. Covvey HD, Zitner D, Bernstein R, MacNeill JE. The development of model curricula for Health Informatics. Stud Health Technol Inform 2001;84(Pt 2):1009-13.

67. Marin HF, Massad E, Marques EP, Azevedo RS, Ohno-Machado L. Health Informatics Education in Brazil. In: Engelbrecht R. et al, editors. Connecting Medical Informatics and Bio-Informatics-ENMI; 2005. p. 1126-31.

68. Jaspers MW, Gardner RM, Gatewood LC, Haux R, Schmidt D, Wetter T. The International Partnership in Health Informatics Education. Stud Health Technol Inform 2004;107(Pt 2):884-8.

69. Karras BT, O'Carroll P, Oberle MW, Masuda D, Lober WB, Robins LS, et al. Development and evaluation of public health informatics at University of Washington. J Public Health Manag Pract 2002;8(3):37-43

70. Moore RA, Berner ES. Comparison of health/ medical informatics curricula against multiple sets of professional criteria. AMIA Annu Symp Proc 2003:942.

71. KagolovskyY, Brillinger K. A systematic approach to using case studies in health informatics education. AMIA Annu Symp Proc 2009;2009:301-5.

72. Brittain JM, Norris AC. Delivery of health informatics education and training. Health Libr Rev 2000;17(3):117-28.

73. Jaspers MW, Gardner RM, Gatewood LC, Haux R, Schmidt D, Wetter T. The International Partnership for Health Informatics Education: lessons learned from six years of experience. Methods Inf Med 2005;44(1):25-31.

74. Huang QR. Competencies for graduate curricula in health, medical and biomedical informatics: a framework. Health Informatics J 2007;13(2):89-103.

75. Buckeridge D. Health Informatics in Canada-Definitios, Education, and the Path Ahead. Report. Canada: University of Toronto; 1999.

76. Jaspers MW, Gardner RM, Gatewood LC, Haux $\mathrm{R}$, Evans RS. An international summer school on health informatics: a collaborative effort of the Amsterdam Medical Informatics Program and I E--the International Partnership for Health Informatics Education. Int J Med Inform 2007:76(7):538-46.

77. Dalrymple PW. Data, information, knowledge: The emerging field of health informatics. Bulletin of the American Society for Information Science and Technology 2011;37(5):41-4.

78. Roger France FH, Beguin C, Mélot C, Gillet P. Board certified physicians in health informatics a European precedent for professional recognition. Yearb Med Inform 2010:116-20.

79. Kushniruk A, Lau F, Borycki E, Protti D. The School of Health Information Science at the University of Victoria: towards an integrative model for health informatics education and research. Yearb Med Inform 2006:159-65.

80. Mantas J. Education and consumer health informatics. Yearb Med Inform 2007:90-4.

81. Marschollek M. Advances in education and consumer health informatics. Findings from the Section on Education and Consumer Informatics. Yearb Med Inform 2007:95-7.

82. Coiera E, Magrabi F, Sintchenko V, Zrimec T, McDonnell G, Chung G, et al. The Centre for Health Informatics at the University of New South Wales--a clinical informatics research centre. Yearb Med Inform 2007:141-8.

83. Haux R. Health care and informatics: on IMIA's opportunities and responsibilities in its 5 th decade. Yearb Med Inform 2008:1-6.

84. Altwaijiri M, Aldosari B. Health Informatics Master Program at King Saud bin Abdulaziz University for Health Sciences, Riyadh, Saudi Arabia. Yearb Med Inform 2008:145-9.

85. Hackbarth G, Cata T, Cole L. Developing a capstone course within a health informatics program. Perspect Health Inf Manag - Summer 2012;9(1b):1-21

86. Foy D, Canfield K, Schwartz J. Undergraduate health care informatics education: a needs analysis and proposed curriculum. Proc Annu Symp Comput Appl Med Care 1994:37-40.

87. Aarts J. A model curriculum of health care informatics for Dutch higher professional education. Proc Annu Symp Comput Appl Med Care 1995:480-3.

88. Covvey HD, Pidduck AB. Health Informatics Education Working Paper. Waterloo HIP Position Paper Final; 2015 Sept.

89. Covvey HD, Zitner D, Bernstein R. Pointing the way: Competencies and curricula in health informatics. Waterloo, Ontario, Canada: University of Waterloo; 2001.

90. Hasman A, Donkers J, Roos S, Muijtjens A, Groothedde RT, Groothuis S, De Moor G, Klar R. International Coordinated Development of Educational Software. In: O'Moore R, Bengtsson S, Bryant JR, Bryden JS, editors. Medical Informatics Europe'90; 1990; Berlin: Springer. 435-9.

91. Zvarova J. On development of medical informatics education via European cooperation. Int J Med Inform 1998:50:219-23.

92. Hasman A. Education and training in health informatics: the IT-EDUCTRA project. Int J Med Inform 1998;50:179-85.

93. Mantas J. The NIGHTINGALE project: an outline. In: Mantas J, editor. Health Telematics Education. Studies in Health Technology and Informatics 1997:41:7-25.

94. Mantas J, editor. Health Telematics Education. Studies in Health Technology and Informatics 1997:41.

95. Mantas J, editor. Advance in Health Telematics Education. Studies in Health Technology and Informatics 1998:51.

96. Mantas J, editor. Health and medical informatics education in Europe. : Studies in Health Technology and Informatics 2000:57. Amsterdam: IOS Press.

97. Mantas J, Hasman A. Textbook in health informatics. A nursing perspective. Studies in Health Technology and Informatics 2002:65. Amsterdam: IOS Press.

98. Ball MJ, Protti DJ, Douglas JV. An international health/medical informatics programs database. Meth Inform Med 1994;33:327-9.

99. Haux R, Frank J, Knaup P. The IMIA WG1 database on health and medical informatics programs and courses: a cal for participation. Methods Inf Med 1997;36:233-4.

100. Mantas J,Ammenwerth E, Demiris G, Hasman A, Haux R, Hersh W, Hovenga E, Lun KC, Marin H, Martin-Sanches F, Wright G. Recommendations of the International Medical Informatics Association (IMIA) on Education in Biomedical and Health Informatics. First Revision. Methods Inf Med 2010;49(2):105-20.

101. Hasman A, Mantas J. IMIA Accreditation of Health Informatics Programs. Healthc Inform Res 2013;19(3):154-61.

102. McDaniel AM, Delaney CW. Training scientists in the nursing informatics research agenda. Nursing Outlook 2007;55(2):115-6.

103. Bürkle T, Schrader U. Two years of German summer school of nursing informatics: Did we reach the goals? Int J Med Inform 2000;58-59:307-17.

104. Mantas J. Developing curriculum in nursing informatics in Europe. Int $\mathrm{J}$ Med Inform 1998;50(1-3):123-32.

105. Liu CH, Lee TT, Mills ME. The experience of informatics nurses in Taiwan. J Prof Nurs 2015;31(2):158-64.

106. Travis LL, Youngblut J. Supporting patient centered computing through an undergraduate nursing informatics curriculum stage III. Proc Annu Symp Comput Appl Med Care 1993:757-61.

107. Saba VK. Nursing informatics: yesterday, today and tomorrow. Int Nurs Rev 2001;48(3):177-87.

108. Bickford CJ, Smith K, Ball MJ, Frantz G, Panniers TL, Newbold SK, et al. Evaluation of a nursing informatics training program shows significant changes in nurses' perception of their knowledge of information technology. Health Informatics J 2005;11(3):225-35.

109. Bond CS, Lewis R, Joy R. Nursing informatics; is IT for all nurses? Nursing Informatics 2009.

110. Chang J, Poynton MR, Gassert CA, Staggers 
N. Nursing informatics competencies required of nurses in Taiwan. Int J Med Inform 2011;80(5):332-40.

111. Chang P, Kuo MC. Taiwan model: nursing informatics training. Nursing Informatics. London: Springer; 2011.

112. Charters KG. Nursing informatics, outcomes, and quality improvement. AACN Advanced Critical Care 2003;14(3):282-94.

113. Currie LM. Evaluation frameworks for nursing informatics. Int $\mathrm{J}$ Med Inform 2005;74(11):908-16.

114. Demiris G, Zierler B. Integrating problem-based learning in a nursing informatics curriculum. Nurse education today 2010;30(2):175-9.

115. Ehnfors M, Grobe SJ. Nursing curriculum and continuing education: future directions. Int J Med Inform 2004;73(7):591-8.

116. Foster J, Bryce J. Australian nursing informatics competency project. In: Saranto K, Brennan P, Park HA, Tallberg M, Ensio A, editors. Proceedings of the 10th International Congress on Nursing Informatics: Connecting Health and Humans. Helsinki: IOS Press BV; 2009.

117. Gassert CA, Mills ME, Heller BR. Doctoral specialization in nursing informatics. Proc Annu Symp Comput Appl Med Care 1991:263-7.

118. Guenther JT. Mapping the literature of nursing informatics. J Med Libr Assoc 2006;94(2 Suppl):92.

119. Kokol P, Zazula D, Brumec V, Kolenc L. Nursing informatics education for the next millenium. Future Generation Computer Systems 1999;15(2):211-6

120. Marin HF, Silveira DT, Dal Sasso G, Perez HHC Evolution: Nursing Informatics in Brazil. In: Nursing Informatics. London: Springer; 2011.

121. Masys DR, Brennan PF, Ozbolt JG, Corn M, Shortliffe EH. Are medical informatics and nursing informatics distinct disciplines? J Am Med Inform Assoc 2000;7(3):304-12.

122. McCartney PR. Leadership in nursing informatics. J Obstet Gynecol Neonatal Nurs 2004;33(3):371-80.

123. McNeil BJ, Odom SK. Nursing informatics education in the United States: proposed undergraduate curriculum. Health Informatics $\mathrm{J}$ 2000;6(1):32-8.

124. McNeil BJ, Elfrink VL, Pierce ST, Beyea SC, Bickford CJ, Averill C. Nursing informatics knowledge and competencies: A national survey of nursing education programs in the United States. Int J Med Inform 2005;74(11):1021-30.

125. Nagle LM, Clarke HF. Assessing informatics in Canadian schools of nursing. Stud Health Technol Inform 2004;107:912-5.

126. Ozbolt JG, Saba VK. A brief history of nursing informatics in the United States of America. Nurs Outlook 2008;56(5):199-205.

127. Ragneskog H, Gerdner L. Competence in nursing informatics among nursing students and staff at a nursing institute in Sweden. Health Info Libr J 2006;23(2):126-32.

128. Saba VK. A look at nursing informatics. Int J Med Inform 1997;44(1):57-60.

129. Saranto K, Leino-Kilpi H. Computer literacy in nursing: developing the information technology syllabus in nursing education. J Adv Nurs
1997;25(2):377-85.

130. Saranto K, Tallberg M. Nursing informatics in nursing education: a challenge to nurse teachers. Nurse Educ Today 1998;18(1):79-87.

131. Schulte SJ. Integrating information literacy into an online undergraduate nursing informatics course: The librarian's role in the design and teaching of the course. Med Ref Serv Q 2008;27(2):158-72.

132. Smedley A. The importance of informatics competencies in nursing: an Australian perspective. Comput Inform Nurs 2005;23(2):106-10.

133. Turley JP. Toward a model for nursing informatics. IMAGE: The Journal of Nursing Scholarship 1996;28(4):309-13

134. Zytkowski ME. Nursing informatics: The key to unlocking contemporary nursing practice. AACN Clin Issues 2003;14(3):271-81.

135. Gerstein M, Greenbaum D, Cheung K, Miller $\mathrm{PL}$. An interdepartmental Ph.D. program in computational biology and bioinformatics: The Yale perspective. J Biomed Inform 2007;40(1):73-9.

136. Friedman CP, Altman RB, Kohane IS, McCormick KA, Miller PL, Ozbolt JG, et al. Training the Next Generation of Informaticians: The Impact of "BISTI" and Bioinformatics-A Report from the American College of Medical Informatics. J Am Med Inform Assoc 2004:11(3):167-72.

137. Altman RB, Klein TE. Biomedical informatics training at Stanford in the 21st century. J Biomed Inform 2007;40(1):55-8.

138. Patel VL, Kannampallil TG. Cognitive informatics in biomedicine and healthcare. J Biomed Inform 2015:53:3-14

139. Haux R. Biomedical and health informatics education at UMIT-approaches and strategies at a newly founded university. Int J Med Inform 2004;73(2):127-38

140. Anderson JG. The role of ethics in information technology decisions: a case-based approach to biomedical informatics education. Int J Med Inform 2004;73(2):145-50.

141. Kane MD, Brewer JL. An information technology emphasis in biomedical informatics education. J Biomed Inform 2007;40(1):67-72.

142. Patel VL, Yoskowitz NA, Arocha JF, Shortliffe EH. Cognitive and learning sciences in biomedical and health instructional design: A review with lessons for biomedical informatics education. J Biomed Inform 2009;42(1):176-97.

143. Bernstam EV, Smith JW, Johnson TR. What is biomedical informatics? J Biomed Inform 2010;43(1):104-10

144. Eikey EV, Reddy MC, Kuziemsky CE. Examining the role of collaboration in studies of health information technologies in biomedical informatics: A systematic review of 25 years of research. J Biomed Inform 2015;57:263-77.

145. van Mulligen EM, Cases M, Hettne K, Molero E, Weeber M, Robertson KA, et al. Training multidisciplinary biomedical informatics students: three years of experience. J Am Med Inform Assoc 2008;15(2):246-54.

146. Marin HF, Ohno-Machado L. Biomedical Informatics: Experience in Brazil and Mozambique. In: Mantas J, Andersen SK, Mazzoleni MC, Blobel B, Quaglini S, Moen A, editors. 24th International Conference of the European
Federation for Medical Informatics Quality of Life through Quality of Information (MIE2012 conference); 2012 Aug; Pisa, Italy. Amsterdam: IOS Press; 2012.

147. Kulikowski CA, Shortliffe EH, Currie LM, Elkin PL, Hunter LE, Johnson TR, et al. AMIA Board white paper: definition of biomedical informatics and specification of core competencies for graduate education in the discipline. J Am Med Inform Assoc 2012;19(6):931-8.

148. Zimmerman JL. Defining biomedical informatics competency: the foundations of a profession. Adv Dent Res 2003;17:25-8.

149. Ritko AL, Odlum M. Gap analysis of biomedical informatics graduate education competencies. AMIA Annu Symp Proc 2013;2013:1214-23.

150. Valerius JD, Hersh WR. How well does a biomedical informatics curriculum map to health information management knowledge clusters? Analysis of a program. AMIA Annu Symp Proc 2008:967.

151. Johnson SB. A framework for the biomedical informatics curriculum. AMIA Annu Symp Proc 2003:331-5.

152. Blas MM, Curioso WH, Garcia PJ, Zimic M, Carcamo CP, Castagnetto JM, et al. Training the biomedical informatics workforce in Latin America: results of a needs assessment. BMJ Open 2011;1(2):e000233.

153. Zvarova J. Biomedical informatics research and education at the EuroMISE Center. Yearb Med Inform 2006:166-73.

154. Severtson DJ, Pape L, Page CD Jr, Shavlik JW, Phillips GN Jr, Flatley Brennan P. Biomedical informatics training at the University of Wisconsin-Madison. Yearb Med Inform 2007:149-56.

155. Tanaka H, Nakaya J. Research and education for biomedical informatics at Tokyo Medical and Dental University. Yearb Med Inform 2007:157-62

156. Greenes RA, Panchanathan S, Patel V, Silverman H, Shortliffe EH. Biomedical informatics in the desert--a new and unique program at Arizona State University. Yearb Med Inform 2008:150-156

157. Wageih MA, Marcano-Cedeño A, Gómez EJ, Mantas J. Toward More Successful Biomedical Informatics Education Programs and Ecosystems in the Arab World. Stud Health Technol Inform 2015;213:111-4.

158. Otero P, Hersh W. Education in Biomedical and Health Informatics in the Web 3.0 Era: Standards for data, curricula, and activities. Contribution of the IMIA Working Group on Health and Medical Informatics Education. Yearb Med Inform 2011;6:139-41.

159. Zvárová J. Education in biomedical informatics and eHealth. Stud Health Technol Inform 2008;134:27-32.

160. Busse R, Rienhoff O. Thirteen Years of a Nation-Wide Curriculum in Medical Informatics: Does it Still Meet the Requirements? Series Lecture Notes in Medical Informatics 1991;45:605-9.

161. Lincoln TL. Medical informatics: the substantive discipline behind health care computer systems. Int J Biomed Comput 1990;26(1-2):73-92.

162. Reichertz PL. Preparing for change: concepts 
and education in medical informatics. Comput Methods Programs Biomed 1987;25(2):89-101.

163. Parsons DF. The case for including medical informatics in medical, nursing, and public health school curricula. Telematics and Informatics 1993;10(2):157-70.

164. Moehr JR. Evaluation: salvation or nemesis of medical informatics? Comput Biol Med 2002;32(3):113-25.

165. Jaspers MW, Hasman A. The new set-up of the medical informatics Master of Science program at the University of Amsterdam. Int J Med Inform 2007;76(3):369-76.

166. Hu D, Sun Z, Li H. An overview of medical informatics education in China. Int J Med Inform 2013;82(5):448-66.

167. Haux R. Preparing for change: medical informatics international initiatives for health care and biomedical research. Comput Methods Programs Biomed 2007;88(3):191-6.

168. Hasman A, Haux R, Albert A. A systematic view on medical informatics. Comput Methods Programs Biomed 1996;51(3):131-9.

169. Friedman CP, Abbas UL. Is medical informatics a mature science? A review of measurement practice in outcome studies of clinical systems. Int J Med Inform 2003;69(2-3):261-72.

170. Logan JR, Price SL. Computer science education for medical informaticians. Int J Med Inform 2004;73(2):139-44.

171. Jaspers MW, Fockens P, Ravesloot JH, Limburg M, Abu-Hanna A. Fifteen years medical information sciences: the Amsterdam curriculum. Int J Med Inform 2004;73(6):465-77.

172. Haux R. Medical informatics: past, present, future. Int J Med Inform 2010;79(9):599-610.

173. Rozenblum R, Donzé J, Hockey PM, Guzdar E, Labuzetta MA, Zimlichman E, et al. The impact of medical informatics on patient satisfaction: a USA-based literature review. Int J Med Inform 2013;82(3):141-58.

174. Zvárová J, Engelbrecht R, van Bemmel JH. Education and training in medical informatics, statistics and epidemiology in EuroMISE. Int J Med Inform 1997;45(1-2):3-8.

175. Hasman A. Challenges for medical informatics in the 21st century. Int J Med Inform 1997:44(1):1-7.

176. Haux R. Aims and tasks of medical informatics. Int J Med Inform 1997;44(1):9-20; discussion 39-44, 45-52, 61-6.

177. Lun KC. Aims and tasks of medical informatics--a commentaryon Reihnold Haux's paper. Int J Med Inform 1997;44(1):61-6.

178. van Bemmel JH, Duisterhout JS. Education and training of medical informatics in the medical curriculum. Int J Med Inform 1998;50(13):49-58.

179. Ishijima M. Medical informatics education by medical professors within their discipline. Int J Med Inform 1998;50(1-3):81-5.
180. Masić I. Education of medical informatics in Bosnia and Herzegowina. Int J Med Inform 1998;50(1-3):95-101.

181. Knaup P, Haux R, Häber A, Lagemann A, Leiner F. Teaching the fundamentals of information systems management in health care. Lecture and practical training for students of medical informatics. Int J Med Inform 1998;50(1-3):195-205.

182. Ireland M, Brown T, Byrne K, McPherson $\mathrm{J}$, Swinkels W. Education in informatics in medicine and the health sciences- the need for relevance. Int J Med Inform 1998;50(1-3):77-80.

183. Lorenzi NM. IMIA Working Group 13: organizational impact of medical informatics. Int J Med Inform 1999;56(1-3):5-8

184. Maojo V, Iakovidis I, Martin-Sanchez F, Crespo J, Kulikowski C. Medical informatics and bioinformatics: European efforts to facilitate synergy. J Biomed Inform 2001;34(6):423-7.

185. Moehr JR, Grant A. Medical informatics and medical education in Canada in the 21st century. Clin Invest Med 2000;23(4):275-80.

186. Patton GA, Gardner RM. Medical informatics education: the University of Utah experience. J Am Med Inform Assoc 1999;6(6):457-65.

187. Lorenzi NM, Gardner RM, Pryor TA, Stead WW. Medical informatics: the key to an organization's place in the new health care environment. J Am Med Inform Assoc 1995;2(6):391-2.

188. Shortliffe EH, Garber AM. Training synergies between medical informatics and health services research: successes and challenges. J Am Med Inform Assoc 2002;9(2):133-9.

189. McGowan JJ. A vertical curriculum in applied medical informatics in support of rural primary-care education. Acad Med 1994;69(5):430-1.

190. Mihalas G, Zvarova J, Kulikowski C, Ball M, van Bemmel J, Hasman A, et al. History of medical informatics in Europe - a short review by different approach. Acta Inform Med 2014;22(1):6-10.

191. Roger FF. About the beginnings of medical informatics in Europe. Acta Inform Med 2014;22(1):11-5.

192. Rose E, Zeiger R, Corley S, Gorman P, Yackel T, Hersh W. Development methodology for a "next generation" medical informatics curriculum for clinicians. AMIA Annu Symp Proc 2003:986.

193. Hersh WR, Bhupatiraju RT, Greene P, Smothers $\mathrm{V}$, Cohen C. Adopting e-learning standards in health care: competency-based learning in the medical informatics domain. AMIA Annu Symp Proc 2006:334-8.

194. Ückert F, Ammenwerth E, Dujat C, Grant A, Haux R, Hein A, et al. Past and next 10 years of medical informatics. J Med Syst 2014;38(7):74.

195. Mantas J, Hasman A. Education in medical informatics and bioinformatics. EJBI 2011:7(2):2011-2

196. Hersh W. Medical informatics education: an alternative pathway for training informationists. J Med Libr Assoc 2002;90(1):76-9.
197. Murphy J. The evolution of undergraduate medical informatics programmes. Health Libr Rev 1994;11(3):167-76.

198. Frisse ME. Medical informatics in academic health science centers. Acad Med 1992;67(4):238-41.

199. Zelnick CJ, Nelson DA. A medical informatics curriculum for 21 st century family practice residencies. Fam Med 2002;34(9):685-91.

200. Woods SE, Coggan JM. Developing a medical informatics education program to support a statewide health information network. Bull Med Libr Assoc 1994;82(2):147-52.

201. Collen MF. Fifty years in medical informatics. Yearb Med Inform 2006:174-9.

202. Bennani Othmani M, Diouny S, Balar K. Medical informatics in Morocco: Casablanca Medical Informatics Laboratory. Yearb Med Inform 2007:138-40

203. Lorenzi NM. 40 Years of IMIA: Shaping Medical Informatics Worldwide. Editorial. Yearb Med Inform 2007;2:163-4.

204. Bouhaddou O, Bennani Othmani M, Diouny S. Medical informatics in morocco. Yearb Med Inform 2013;8:190-6.

205. Chouvarda I, Maglaveras N. Medical Informatics Education \& Research in Greece. Yearb Med Inform 2015;10(1):220.

206. Moidu K, Leehy MA, Steinberg I, Einreinhofer S, Falsone JJ, Cleary J, et al. Informatics integration in a medical residency program: early experiences. Proc AMIA Annu Fall Symp 1996:55-9.

207. Chi X, Pavilcek K. A hypergraphic model of medical informatics: curriculum development guide. Proc AMIA Symp 1999:37-41.

208. McGowan J, Raszka W, Light J, Magrane D, O'Malley D, Bertsch T. A vertical curriculum to teach the knowledge, skills, and attitudes of medical informatics. Proc AMIA Symp 1998:457-61.

209. Espino JU, Levine MG. An overview of the medical informatics curriculum in medical schools. Proc AMIA Symp 1998:467-71.

210. Hasman A. Education and medical informatics--five years of experience at the University of Limburg. Proc Annu Symp Comput Appl Med Care 1991:273-7.

211. Frisse ME. Re-imagining the medical informatics curriculum. Acad Med 1997;72(1):36-41

212. Sarbadhikari SN. The state of medical informatics in India: a roadmap for optimal organization. J Med Syst 2005;29(2):125-41.

Correspondence to:

John Mantas

Health Informatics Laboratory

Department of Nursing

School of Health Sciences

National and Kapodistrian University of Athens

Greece

E-mail: jmantas@nurs.uoa.gr 